\title{
MORFOANATOMIA E HISTOQUÍMICA FOLIAR DE Diodella teres (Walter) Small
} (RUBIACEAE)

\author{
Luena de Oliveira da Conceiçãó ${ }^{1}$, Elisa Mitsuko Aoyama ${ }^{1}$
}

1 Departamento de Ciências Agrárias e Biológicas, Centro Universitário Norte do Espírito Santo, Universidade Federal do Espírito Santo Rodovia BR 101 Norte km 60, Litorâneo, São Mateus, ES, Brasil, CEP 29932-540 (luena09@gmail.com) Recebido em: 08/09/2015 - Aprovado em: 14/11/2015 - Publicado em: 01/12/2015
DOI: http://dx.doi.org/10.18677/Enciclopedia_Biosfera_2015_197

A Rubiaceae Juss. é cosmopolita, porém mais diversa em regiões tropicais e subtropicais. Diodella teres (Walter) Small, espécie pertencente a esta família é frequente na região Centro-Oeste e Sudeste do território brasileiro e apresenta preferência por solos arenosos. Por ser uma espécie invasora de ampla ocorrência e pouco estudada, o trabalho tem por objetivo descrever a morfoanatomia foliar de Diodella teres atrelada a testes histoquímicos, visando contribuir para estudos de controle e identificação da espécie. Para descrição morfológica foram avaliadas filotaxia, venação, forma do limbo, ápice, base e margem. Para biometria 30 folhas foram avaliadas quanto aos parâmetros comprimento e largura do limbo. As análises anatômicas foram realizadas segundo técnicas usuais de anatomia. Para os testes histoquímicos, secções transversais da lâmina foliar foram tratadas com sudan IV, solução aquosa de cloreto férrico e solução de floroglucina ácida. Diodella teres apresenta folhas simples, sésseis, anfiestomáticas, epiderme papilosa e tricomas tectores unicelulares em toda extensão foliar. Pode-se concluir que estômatos paracíticos, feixes vasculares do tipo colateral e mesofilo dorsiventral são comuns em espécies de Rubiaceae. Em Diodella teres a deposição de colênquima angular no bordo pode diferenciá-la da $D$. radula, auxiliando na identificação. A grande quantidade de tricomas, baixa quantidade de estômatos e cutícula espessa na face adaxial, são estruturas que podem interferir no controle da espécie. Os testes histoquímicos revelaram presença de lignina, lipídios totais e compostos fenólicos não estruturais, substâncias que podem contribuir para a resistência da espécie ao ambiente.

PALAVRAS - CHAVE: biometria, descrição morfológica, planta daninha, testes histoquímicos.

\section{LEAF MORPHOANATOMY AND HISTOCHEMISTRY OF Diodella teres (Walter) Small (RUBIACEAE)}

\footnotetext{
ABSTRACT

Despite being cosmopolitan, the family Rubiaceae Juss. is more diverse in tropical and subtropical regions. Diodella teres (Walter) Small, species that belongs to this family, is common in the Midwest and Southeast regions of Brazil and it shows preference for sandy soils. Due to being a widely spread invasive species and being poor studied, this study aimed to describe the leaf morphoanatomy of Diodella teres 
linked to histochemical tests, in order to contribute to future studies of control and identification of this species. For morphological description, the phyllotaxy, venation, leaf shape, apex, base and margin were analysed. For biometry, 30 leaves were measured in length and width parameters of leaf. The anatomical analyses were performed according to standard techniques of anatomy. For histochemical tests, cross sections of the leaf blade were treated with sudan IV, aqueous solution of ferric chloride and acid phloroglucin. Diodella teres has simple, sessile and amphistomatic leaves, papillose epidermis and trichomes unicellular throughout leaf extension. It can be concluded that paracytic stomata, collateral vascular bundles type and mesophyll dorsoventrally are common in Rubiaceae's species. In Diodella teres deposition of angle collenchyma at the board can differentiate it from $D$. radula, assisting in the identification. The large amount of trichomes, low amount of stomata and thick cuticle on the adaxial face, are structures that can interfere in the control of the species. The histochemical tests revealed the presence of lignin, total lipids and non-structural phenolic compounds, substances that may contribute to the species' environmental resistance.

KEYWORDS: biometrics, morphological description, weed, histochemical tests

\section{INTRODUÇÃO}

A família Rubiaceae Juss. é cosmopolita, porém mais diversa em regiões tropicais e subtropicais. Possui aproximadamente 9.000 espécies, incluídas em 550 gêneros (JUDD et al., 2009). No Brasil, a família está representada por 125 gêneros e 1.406 espécies, dos quais 17 gêneros e 781 espécies são endêmicos (BARBOSA et al., 2014). Possuem representantes desde árvores, arbustos, subarbustos, ervas, trepadeiras, lianas até epífitas, apresentando folhas simples, inteiras, opostas, decussadas, verticiladas, raro alternas; estípulas interpeciolares; domácias presentes ou não. Inflorescência terminal ou axilar, paniculada a cimosa, racemosa, capitada ou espiciforme, até flor solitária (WANDERLEY et al., 2007).

Dentre as Rubiaceae ocorrem espécies com grande importância econômica, destacando-se Coffea arabica e C. robusta, que a partir de suas sementes obtém-se o café (JUDD et al., 2009). Espécies com flores vistosas, com potencial ornamental como Gardenia augusta (L.) Merr., Hamelia patens Jacq., Ixora chinensis Lam. Manettia cordifolia Mart., Mussaenda erythrophylla Schumach., Pentas lanceolata (Forssk), Randia formosa (Jacq.) K. Schum. Serissa foetida (L.f.) Poir. Ex Lam., Tocoyena bullata (Vell.) Mart. e Galianthe brasiliensis (Spreng.) E. L. Cabral \& Bacigalupo, Sin.: Diodia brasiliensis Spreng. (LORENZI \& SOUZA, 2008).

A partir do uso popular, algumas espécies tem emprego medicinal, como: Carapichea ipecacuanha (Brot.) L. Andersson, Chiococca alba (L.) Hitchc., Cinchona calisaya Wedd., Coffea arabica L., Coutarea hexandra (Jacq.) K. Schum., Genipa americana L. Hamelia patens Jacq. Spermacoce verticillata L., e Uncaria guianensis (Aubl.) J.F. Gmel. (LORENZI; MATOS, 2008). O quinino, um fármaco utilizado no tratamento da malária, provém da casca de espécies de Cinchona. A iperac, uma substância utilizada para induzir o vômito, provém de Psychotria (ipeca-cuãnha).

Outras espécies podem ser consideradas como daninhas, por apresentarem crescimento rápido e intenso, podendo afetar o desenvolvimento de plantas cultivadas, dentre elas, além de Diodella teres, ocorrem Diodia saponariifolia (Cham. \& Schltdl) K. Schum., Mannettia cordifolia Mart., Mitracarpus hirtus, Palicourea marcgravii St. Hil., Richardia brasiliensis Gomes, e Spermacoce capitata Ruiz \& Pav. (LORENZI, 2000). 
Diodella teres (Walter) Small, espécie pertencente a esta família, é nativa do continente americano, conhecida popularmente como mata-pasto, quebra-tijela-defolha-estreita, corre-mundo. Planta frequente na região Centro-Oeste e Sudeste do território brasileiro, apresenta nítida preferência por solos arenosos como os de antigos cerrados (LORENZI, 2000; WANDERLEY et al., 2007).

São ervas anuais que apresentam comprimento de $30-50 \mathrm{~cm}$, crescem de forma prostrada ou ereta com ramos ramificados e pilosos (WANDERLEY et al. 2007).

Diodella teres já foi retratada por outros autores como MUSSURY et al. (2012) na qual descreveram a morfoanatomia de Diodella radula e $D$. teres com intuito de determinar as estruturas que podem influenciar na absorção de herbicidas e GAO et al. (2010) que descreveram e ilustraram os caracteres morfológicos de $D$. teres com finalidade de aprimorar os estudos taxonômicos da espécie.

Por ser uma espécie invasora de ampla ocorrência e pouco estudada, o trabalho tem por objetivo descrever a morfoanatomia foliar de Diodella teres atrelada a testes histoquímicos, visando contribuir para estudos de controle e de identificação da espécie.

\section{MATERIAL E MÉTODOS}

Ramos de Diodella teres (Walter) Small foram coletados no campus da Universidade Federal do Espírito Santo em São Mateus-ES (S 18 40.467'- W 03951.796'). Parte do material foi depositado no herbário VIES do Centro Universitário Norte do Espírito Santo (CEUNES) sob o número 29944.

As análises morfoanatômicas foram conduzidas no laboratório de Botânica do Centro Universitário Norte do Espírito Santo, Universidade Federal do Espírito Santo utilizando-se folhas adultas retiradas do $5^{\circ}$ a 9ํㅡós.

A análise morfológica foi realizada com base na terminologia das obras de HICKEY (1973) e SOUZA et al. (2013) e os seguintes parâmetros foram avaliados: filotaxia, venação, forma do limbo, forma do ápice, forma da base e margem. Para biometria foram avaliadas 30 folhas quanto aos parâmetros: comprimento e largura do limbo, sendo calculados a média e o desvio padrão.

Para as análises anatômicas as folhas foram fixadas em FAA (formaldeído: ácido acético: álcool etílico, 70\%, 2:1:18, v/v), de acordo com JOHANSEN (1940), por 48 horas e, posteriormente armazenadas em álcool $70 \%$, e seccionadas no sentido transversal e paradérmico a mão livre com auxílio de lâmina de barbear e isopor. Em seguida, as secções foram clarificadas em solução de hipoclorito de sódio a $25 \%$ e lavadas com água destilada e, imediatamente, foram coradas com safranina e azul de alcian 1\% (LUQUE et al., 1996). Após análise do material, lâminas semipermanentes foram confeccionadas com gelatina glicerinada.

Para as análises histoquímicas, secções transversais da lâmina foliar fixadas, não clarificadas, foram tratadas com: Sudan IV em etanol para lipídeos totais (PEARSE, 1972); solução aquosa de cloreto férrico para marcação de compostos fenólicos não estruturais (JOHANSEN, 1940) e solução de floroglucina ácida para compostos fenólicos estruturais (lignina) (JOHANSEN, 1940), com base na obra de KRAUS; ARDUIN (1997).

As lâminas foram analisadas ao microscópio óptico e as imagens obtidas em microscópio Motic BA 210, acoplada à câmera fotográfica Moticam 3.0MP, com projeção de escalas micrométricas. 


\section{Descrição morfológica}

\section{RESULTADOS E DISCUSSÃO}

Os indivíduos de Diodella teres exibem folhas simples, sésseis, com filotaxia oposta (Figura 1A), venação camptódromo-eucamptódromo, superfície pilosa em ambas as faces, forma do limbo elíptica a oblonga, ápice agudo a acuminado, base obtusa e bordo inteiro (Figura 1B e 1C). Tais características morfológicas variam se comparadas a descrições feitas por outros autores como MUSSURY et al. (2012) na qual descreveram forma do limbo lanceolado-linear, ápice acuminado e base atenuada de indivíduos de $D$. teres coletadas em Mato Grosso do Sul, e por GAO et al. (2010) que descreveram formato do limbo ovado ou elíptico, ápice acuminado, base amplamente cuneada e margem ciliada em indivíduos coletados na província de Fujian na China. Estas diferenças na morfologia foliar podem ocorrer devido a alterações ambientais.

Nas análises biométricas do limbo, a média, amplitude e desvio padrão foram respectivamente: comprimento $3,43 \mathrm{~cm}(3-3,8 \mathrm{~cm}) \pm 0,218$; largura $1,05 \mathrm{~cm}(0,9-1,2$ $\mathrm{cm}) \pm 0,08$. Através dos dados, observa-se que não há grande variação de comprimento e largura do limbo entre os diferentes nós. WANDERLEY et al. (2007) em trabalho realizado no estado de São Paulo, descreveram Diodella teres com lâmina 1,5-3,2 x 0,2-0,5 cm. GAO et al. (2010), descreveram a lâmina com 1,5-2,8 $\mathrm{cm}$ de comprimento e 0,25-0,45 cm de largura. MUSSURY et al. (2012), descreveram a lâmina com 1,5-4 x 0,5-1 cm. A diferença nos dados biométricos entre os trabalhos de $D$. teres podem ser explicados pelo fato de que os autores dos estudos aqui citados, não informaram o nó das folhas retiradas para biometria, outros fatores também podem influenciar para as diferenças nestes dados, como as condições climáticas e do solo.
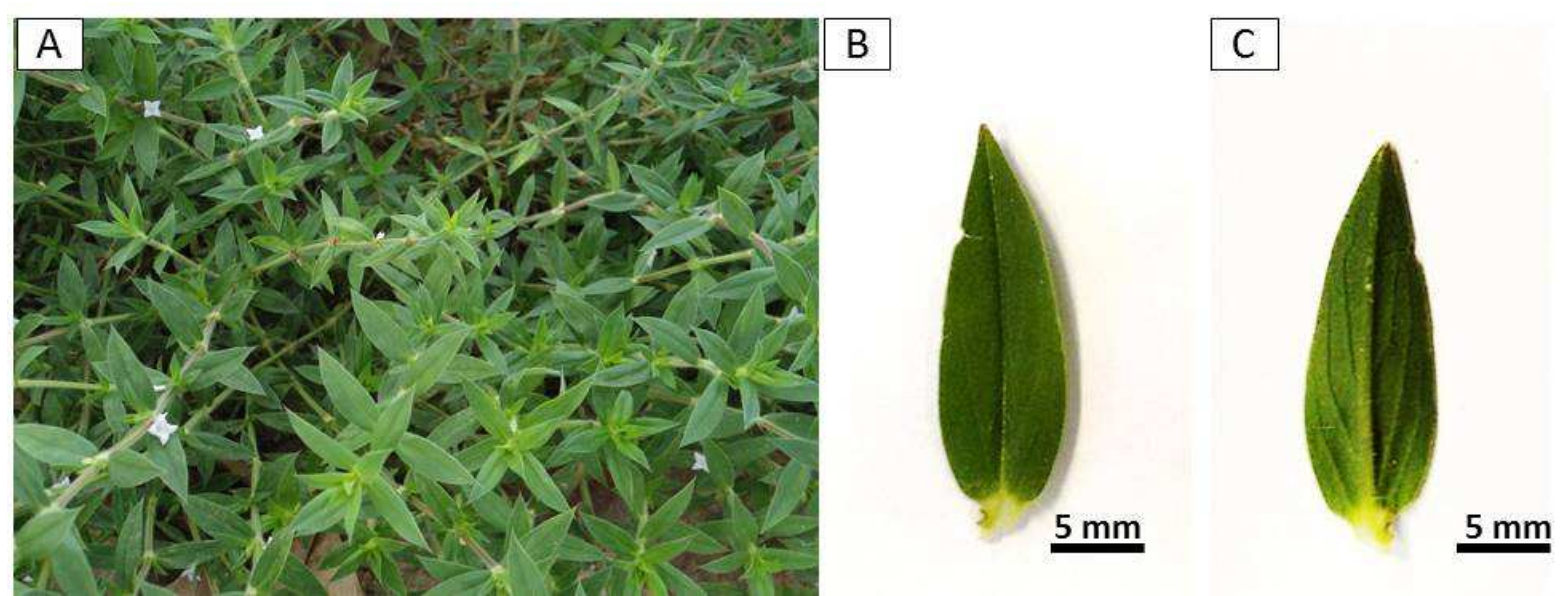

FIGURA 1. Diodella teres. A. Aspecto geral do indivíduo. B. Face adaxial da folha. C. Face abaxial da folha.

FONTE: Luena de Oliveira da Conceição.

\section{Descrição anatômica}

Em vista frontal, as folhas de Diodella teres exibem células epidérmicas com parede anticlinal sinuosa, sendo esta sinuosidade mais evidente na face abaxial (Figura 2A e 2B).

As folhas são anfiestomáticas e apresentam estômatos do tipo paracítico, visivelmente em menor quantidade na face adaxial (Figura 2A e 2B). Diferente de 
Diodia scandens que apresenta quatro tipos de estômatos: diacítico, anisocítico, paracítico, e paracítico com células curtas, sendo diacíticos e paracíticos os mais frequentes. Eles ocorrem individualmente ou os diferentes tipos são colocados lado a lado, numa mesma superfície foliar (ESSIETT et al., 2010).

Segundo MUSSURY et al. (2012) a baixa densidade de estômatos e a espessura da cutícula da superfície adaxial observada em $D$. radula e $D$. teres, parece ser barreira da folha para dificultar a penetração de herbicidas.

Apenas tricomas do tipo tectores unicelulares são observados em toda extensão foliar (Figura 2A e 2B), em ambas as faces, diferente do observado por MUSSURY et al. (2012) na qual descreveram a presença de tricomas glandulares em Diodella teres e por ESSIETT et al. (2010) que descreveram tricoma peltado na face abaxial em Diodia scandens.

Nas análises anatômicas, em secção transversal, as folhas apresentam epiderme papilosa uniestratificada, na qual em vista frontal da face adaxial, pela presença de uma cutícula mais espessa, apresenta aspecto estriado, enquanto na face abaxial, é menos evidente, controverso a definição de papilas (Figura 2D, 2E e $2 \mathrm{~F})$.

Segundo ALQUINI et al. (2003) papilas são pequenas projeções da parede periclinal externa das células epidérmicas, com forma variada que encontram-se na face abaxial das folhas e, quando se localizam próximas aos estômatos, podem possuir ramificações, como em Spartina densiflora. A função das papilas ainda é controversa. Para vários autores a sua importância é apenas taxonômica, enquanto outros acreditam que as papilas possam refletir a luz solar. Epidermes simples papiladas são encontradas em outras plantas daninhas, como a Euphorbia heterophylla (Euphorbiaceae) e a Nicandra physaloides (Solanaceae) (PROCÓPIO et al., 2003)

As superfícies foliares são capazes de ajudar na redução de perda de água, exceto nos ambientes mais úmidos. Em várias espécies, essa necessidade é auxiliada pela presença da cutícula, que retarda a perda de água. A cutícula tende a ser fina em espécies normalmente não sujeitas a estresse hídrico e espessa em espécies propícias a este tipo de estresse (CUTLER et al., 2011).

A nervura central apresenta células epidérmicas com formato ovaladas. $\mathrm{O}$ sistema vascular é constituído por feixe do tipo colateral (Figuras 2C, 3A e 3B), diferente de Diodia scandens que apresenta feixe vascular bicolateral (ESSIETT et al., 2010).

O limbo é dorsiventral com uma a duas camadas de parênquima paliçádico (face adaxial) e duas a três camadas de parênquima lacunoso (face abaxial) (Figura 2E). Tais características também foram observadas por outros autores (ESSIETT et al., 2010; MUSSURY et al., 2012). Em D. radula também ocorre deposição de colênquima angular, porém apenas na nervura central (MUSSURY et al., 2012).

$\mathrm{O}$ bordo foliar apresenta células epidérmicas ovaladas (Figuras $2 \mathrm{~F}$ e $5 \mathrm{D}$ ). Nesta região ocorrem pequenos feixes vasculares, corroborando com a descrição feita por MUSSURY et al. (2012).

$\mathrm{Na}$ face adaxial da nervura central e no bordo observa-se deposição de colênquima angular (Figuras $2 \mathrm{C}$ e $2 \mathrm{~F}$ ). Diferente de $D$. radula que apresenta colênquima apenas na nervura central (MUSSURY et al., 2012).

Dos caracteres apresentados neste estudo, quanto a morfologia, folhas opostas, sésseis, e margem inteira se assemelham a descrições feitas por outros autores (GAO et al., 2010; MUSSURY et al., 2012), características anatômicas como presença de estômatos paracíticos, epiderme papilosa e paredes sinuosas nas ENCICLOPÉDIA BIOSFERA, Centro Científico Conhecer - Goiânia, v.11 n.22; p.2272 2015 
superfícies abaxial e adaxial também são descritos para D. teres (MUSSURY et al., 2012).

O teste histoquímico para detecção de lignina foi positivo nas células do xilema, confirmado pela mudança de coloração das paredes celulares para vermelho a lilás (Figuras 3A e 3B). Segundo SALIBA et al. (2001) a lignina é uma substância com um importante papel no transporte de água, nutrientes e metabólitos, sendo responsável pela resistência mecânica de vegetais, além de proteger os tecidos contra o ataque de microorganismos.
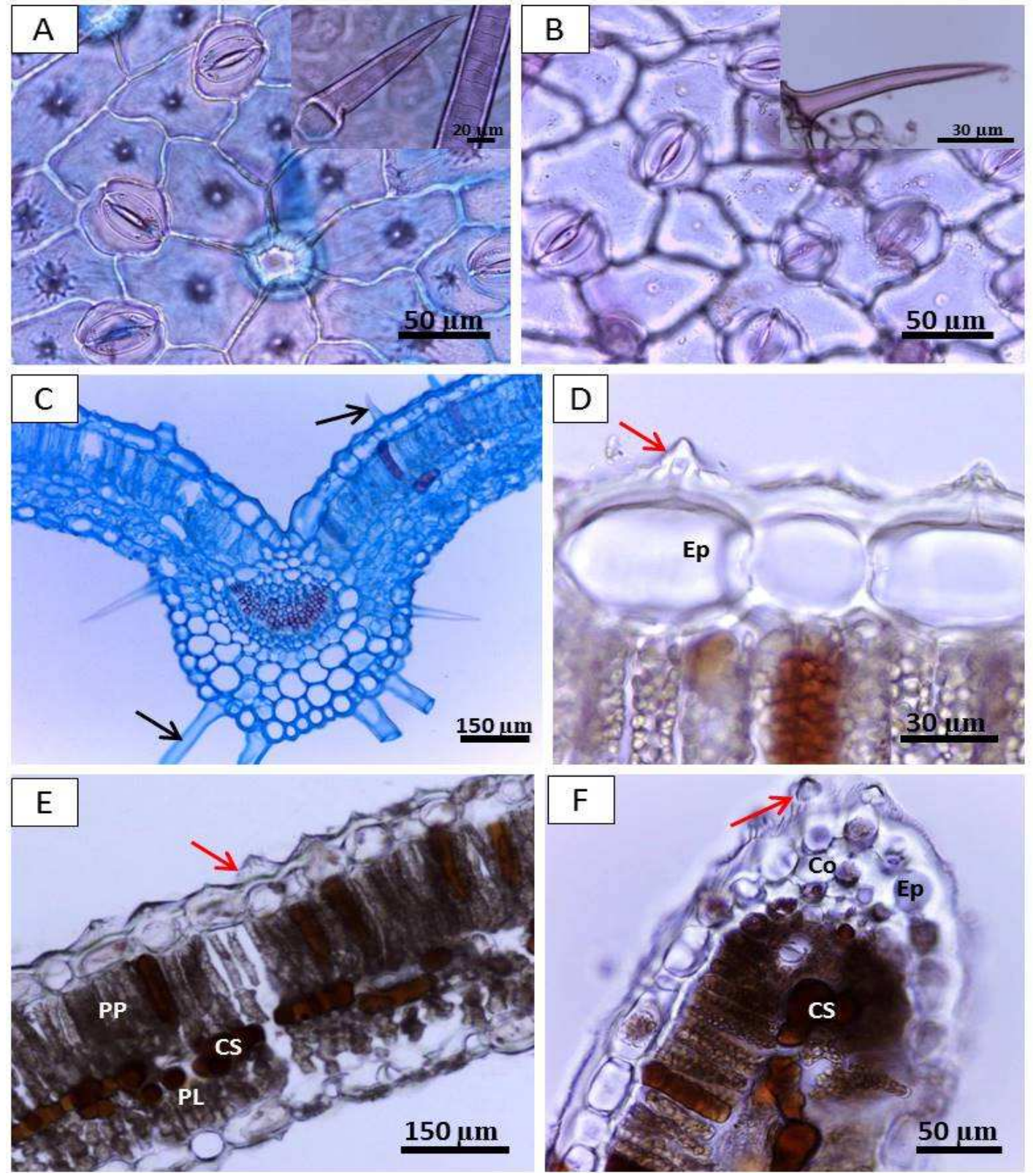

FIGURA 2. Secções paradérmicas e transversais de Diodella teres. A-B. Vista frontal. A. Face adaxial (detalhe de tricoma tector unicelular). B. Face abaxial (detalhe de tricoma tector unicelular). C. Vista geral da nervura central (setas: tricoma tector unicelular). D. Detalhe da epiderme na região do mesofilo. E. Mesofilo. F. Bordo. Setas vermelhas: papilas; Ep: Epiderme; Co: Colênquima; PP: Parênquima Paliçádico; PL: Parênquima Lacunoso; CS: Célula Secretora. FONTE: Luena de Oliveira da Conceição. 
Para lipídios o teste foi positivo na cutícula, nos tricomas tectores, nos elementos de vaso do xilema na nervura central e nas células do parênquima paliçádico em forma de gotículas, confirmado pela mudança de coloração para alaranjado (Figuras 4A e 4B). Gotículas de lipídios também ocorrem no mesofilo de outras espécies de Rubiaceae como, Posoqueria latifolia e Guettarda viburnoides (ALEXANDRINO et al., 2011). Segundo FIGUEIREDO et al. (2007) as reservas lipídicas encontram-se, em geral, sob a forma de gotículas dispersas no citoplasma. As ceras e as cutículas são igualmente ricas em compostos lipídicos e seus derivados.
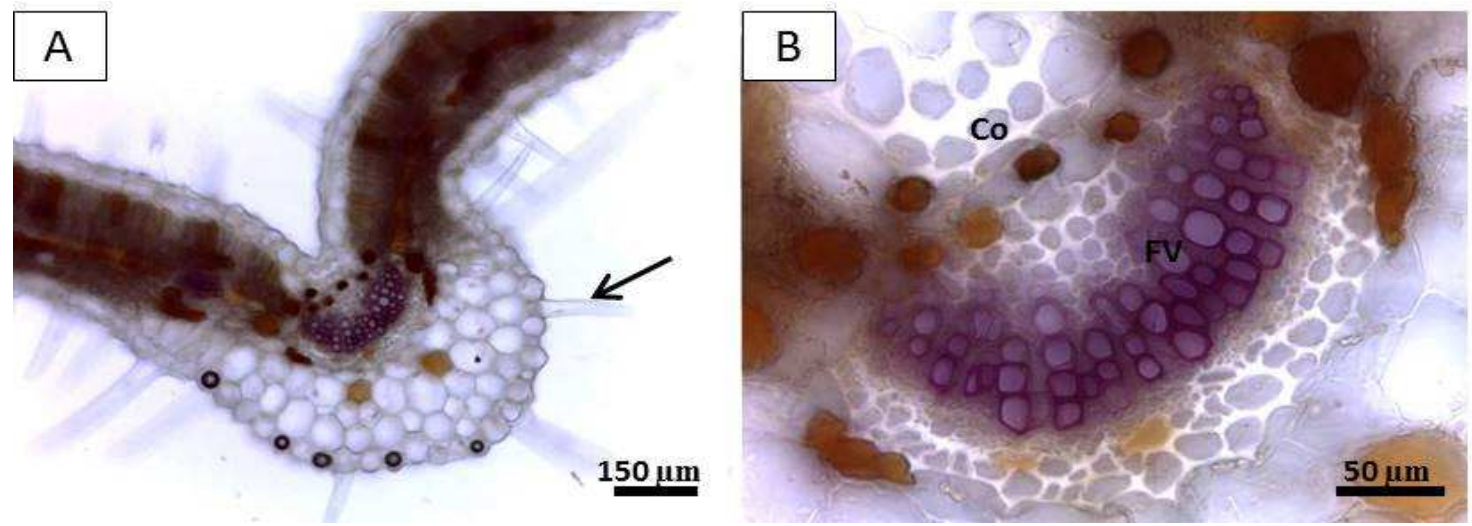

FIGURA 3. Secções transversais da nervura central de Diodella teres submetida à floroglucina ácida para detecção de lignina. A. Vista geral da nervura central (Seta: tricoma tector unicelular). B. Detalhe da nervura Central. Co: Colênquima; FV: Feixe Vascular. FONTE: Luena de Oliveira da Conceição.
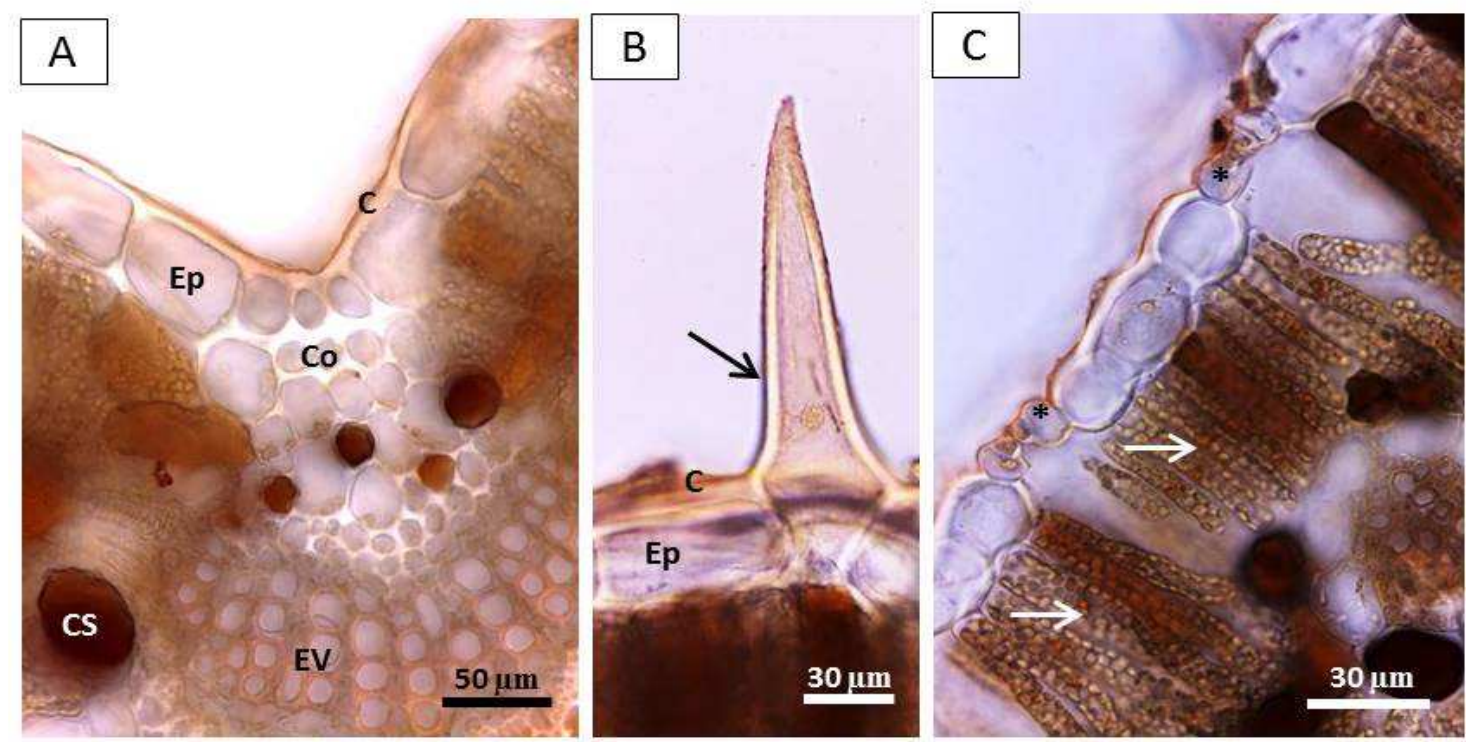

FIGURA 4. Secções transversais de Diodella teres submetidas à Sudan IV para detecção de lipídios totais. A. Detalhe da nervura central. B. Detalhe da epiderme na região do mesofilo evidenciando o tricoma tector unicelular (seta). C. Detalhe do mesofilo evidenciando gotículas de lipídios nas células do parênquima paliçádico (setas). C: Cutícula; Ep: Epiderme; Co: Colênquima; CS: Célula Secretora; EV: Elemento de Vaso. Asteriscos $\left(^{*}\right)$ : Estômato. FONTE: Luena de Oliveira da Conceição. 
Para compostos fenólicos o teste foi positivo nas células secretoras presentes entre as células do mesofilo e na nervura central, confirmado pela mudança de coloração para marrom a negro (Figuras 5A e 5D).

A função dos compostos fenólicos está envolvida com a síntese das ligninas que são comuns a todas as plantas superiores, atrativos aos seres humanos devido ao odor, sabor e coloração agradáveis, mas também para outros animais, os quais são atraídos para polinização ou dispersão de sementes. Além disso, esse grupo de compostos é importante para proteger as plantas contra os raios ultravioletas, insetos, fungos, vírus e bactérias (CROTEAU et al., 2000).

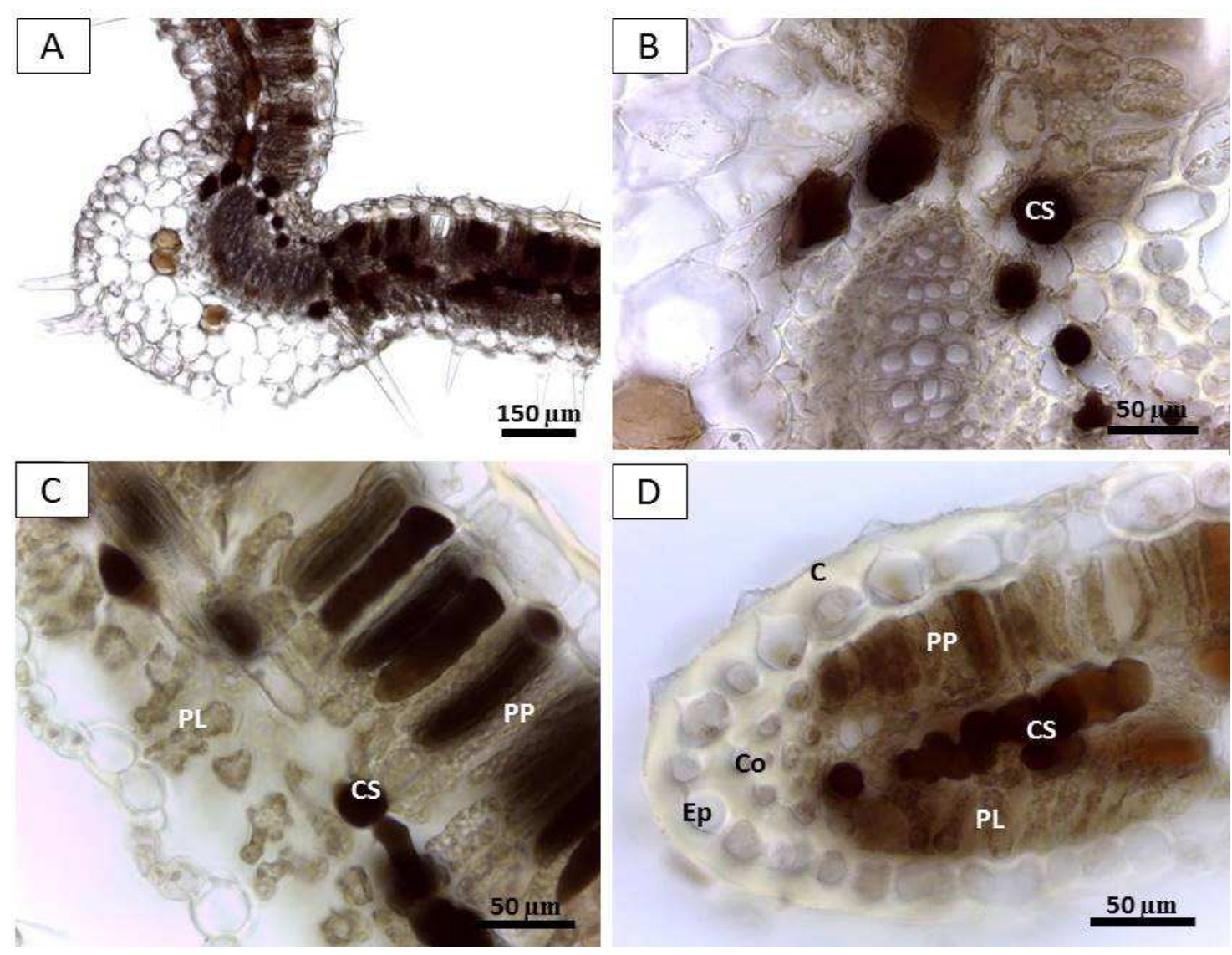

FIGURA 5. Secções transversais de Diodella teres submetidas à cloreto férrico para detecção de compostos fenólicos. A. Vista geral da nervura central. B. Detalhe da nervura central evidenciando a presença de compostos nas células secretoras (CS). C. Detalhe do mesofilo. D. Bordo. C: Cutícula; Ep: Epiderme; Co: Colênquima; PP: Parênquima Paliçádico; PL: Parênquima Lacunoso. FONTE: Luena de Oliveira da Conceição.

\section{CONCLUSÃO}

Pode-se concluir que estômatos paracíticos, feixes vasculares do tipo colateral e mesofilo dorsiventral são comuns em espécies de Rubiaceae.

Em Diodella teres a deposição de colênquima angular no bordo pode diferenciá-la da $D$. radula, auxiliando na identificação. 
A grande quantidade de tricomas na superfície foliar, baixa quantidade de estômatos e cutícula espessa na face adaxial, são estruturas que podem interferir no controle da espécie.

Os testes histoquímicos revelaram presença de lignina, lipídios e compostos fenólicos que são substâncias que podem contribuir para a resistência da espécie ao ambiente.

\section{REFERÊNCIAS}

ALEXANDRINO, C. R.; MORAES, T. M. S.; DA CUNHA, M. Micromorfologia e Anatomia Foliar de Espécies de Rubiaceae do Parque Nacional de Itatiaia-RJ. Floresta e Ambiente. v. 18, n. 3, p. 275-288, 2011.

ALQUINI, Y.; BONA, C.; BOEGER, M. R. T.; COSTA, C. G.; BARROS, C. F. Epiderme. In: APPEZZATO-DA-GLÓRIA; CARMELLO-GUERREIRO, S. M. (Orgs.). Anatomia vegetal, Viçosa: Ed. UFV, p. 87-97, 2003.

BARBOSA, M. R.; ZAPPI, D.; TAYLOR, C.; CABRAL, E.; JARDIM, J. G.; PEREIRA, M. S.; CALIÓ, M. F.; PESSOA, M. C. R.; SALAS, R.; SOUZA, E. B.; DI MAIO, F. R.; MACIAS, L.; ANUNCIAÇÃO, E. A. DA; GERMANO FILHO, P.; OLIVEIRA, J. A.; BRUNIERA, C. P.; M. GOMES; TONI, K. Rubiaceae in Lista de Espécies da Flora do Brasil. Jardim Botânico do Rio de Janeiro. 2014. Disponível em: $<$ http://floradobrasil.jbrj.gov.br/jabot/floradobrasil/FB210>. Acesso em: 05 Junho 2014.

CROTEAU, R.; KUTCHAN, T. M.; LEWIS, N. G. Natural Products (Secondary Metabolites). In: BUCHANAN, B.; GRUISSEM, W.; JONES, R. (Eds.). Biochemistry \& Molecular Biology of Plants, Rockville: American Society of Plant Physiologist, p. 1250-1318, 2000.

CUTLER, D. F.; BOTHA, T.; STEVENSON, D. W. Anatomia vegetal: uma abordagem aplicada. Porto Alegre: Artmed, 2011. 304p.

ESSIETT, U. A., BALA, D. N.; AGBAKAHI, J. A. Pharmacognostic Studies of the Leaves and Stem of Diodia scandens Sw in Nigeria. Scholars Research Library, v.2, n. 5, p. 184-198, 2010.

FIGUEIREDO, A. C. S., BARROSO, J. M. G., PEDRO, L. M. G.; ASCENSÃO, L. Histoquímica e citoquímica em plantas: princípios e protocolos. Lisboa: Faculdade de Ciências da Universidade de Lisboa, Centro de Biotecnologia Vegetal. 2007. 68p.

GAO, Y.; WANG, R.; PENG, C. Diodia teres Walt. (Rubiaceae), a Newly Record Weed in Fujian. Taiwania, v. 55, n. 2, p.177-179, 2010.

HICKEY, L. J. Classification of the Architecture of Dicotyledonous Leaves. American Journal of Botany, v.1, p.17-33. 1973.

JOHANSEN, D. A. Plant Microtechniche. Mc Graw Hill. New York. 1940.

JUDD, W. S.; CAMPBELL, C. S.; KELLOGG, E. A.; STEVENS, P. F. S.; DONOGHU, M. J. Sistemática vegetal: um enfoque filogenético. 3 ed. Porto Alegre: Artmed. 
2009. 632p.

KRAUS, J. E.; ARDUIN, M. Manual básico de métodos em morfologia vegetal. Seropédica, Rio de Janeiro: EDUR. 1997.

LORENZI, H. Plantas daninhas do Brasil: terrestres, aquáticas, parasitas e tóxicas. 3.ed. Nova Odessa, SP: Instituto Plantarum. 2000. 608p.

LORENZI, H.; MATOS, F. J. A. Plantas medicinais no Brasil: nativas e exóticas. 2. ed. Nova Odessa- SP: Instituto Plantarum, 2008. 544 p.

LORENZI, H.; SOUZA, H. M. Plantas ornamentais no Brasil: arbustivas, herbáceas e trepadeiras. 4.ed. Nova Odessa, SP: Instituto Plantarum. 2008. 1088 p.

LUQUE, R., SOUSA, H. C.; KRAUS, J. E. Métodos de coloração de Roeser (1972) modificado e Kropp (1972) visando a substituição do azul de astra pelo azul de alcião 8GS ou 8GX. Acta Botanica Brasilica, v. 10, n. 2, p. 199-212, 1996.

MUSSURY, R. M.; PEREIRA, Z. V.; SCALON, S. P. Q. Comparison of leaf morphoanatomy of Diodella radula (Willd. \& Hoffmanns. ex Roem. \& Schult.) Delprete and Diodella teres (Walter) Small (Rubiaceae). International Journal of Plant Research, v. 2, n. 2, p.41-45, 2012.

PEARSE, A. G. E. Histochemistry: theoretical and applied. 3. ed. Baltimore, Williams \& Wilkins, 1972.

PROCÓPIO, S. O.; SILVA, E. A. M.; SILVA, A. A.; FERREIRA, E. A. Anatomia foliar de plantas daninhas do Brasil. Viçosa: UFV, 2003.118p.

SALIBA, E. O. S.; RODRIGUEZ, N. M.; MORAIS, S. A. L.; PILÓ-VELOSO, D. Ligninas - métodos de obtenção e caracterização química. Ciência Rural, Santa Maria, v. 31, n. 5, p. 917-928, 2001.

SOUZA, V. C.; FLORES, T. B.; LORENZI, H. Introdução à botânica: morfologia. Nova Odessa- SP: Instituto Plantarum, 2013. 224p.

WANDERLEY, M. G. L.; SHEPHERD, G. J.; MELHEM, T. S.; GIULIETTI A. M. Flora Fanerogâmica do Estado de São Paulo. Instituto de Botânica: São Paulo. v. 5, 2007. 476p. 